\title{
Modelling the effects of salinity variation on Echinogammarus marinus Leach (Amphipoda, Gammaridae) density and biomass in the Mondego Estuary (Western Portugal)
}

\author{
Irene Martins *, Paulo Maranhão, João Carlos Marques \\ IMAR_Institute of Marine Research, Department of Zoology, Faculty of Sciences and Technology, University of Coimbra, \\ 3004-517, Coimbra, Portugal
}

Received 22 June 2001; received in revised form 21 November 2001; accepted 20 December 2001

\begin{abstract}
Echinogammarus marinus (Amphipoda, Gammaridae) is the most abundant amphipod species in the intertidal rocky habitats of the Mondego estuary and it seems to constitute an important prey for upper trophic levels. The aim of the present model was to assess the impacts of salinity variations on the abundance and biomass of E. marinus. For model purposes, the size structure of the population was divided in four different groups: juveniles, young females, adult females and males, which constitute the model state variables expressed as density (number of individuals $\mathrm{m}^{-2}$ ). The variation of the density of each group over time depends on growth, mortality and reproduction/recruitment. Simultaneously, the model also calculates the biomass of each group, by taking into consideration the density and the average weight of each group through time. The model accounts for a dependency of population density on biomass, since the number of newly hatched juveniles depends on female cephalic length and, consequently, on female size. Population growth is estimated according to a Von Bertalanffy model, which takes into account anabolism and catabolism effects. Moreover, E. marinus growth is considered as temperature-dependent, while recruitment is considered as temperature- and salinity-dependent. Model results suggest that E. marinus density is seriously affected by low salinity $(<5)$ and that the negatives effects increase with increasing time of exposition to low salinity. According to the model, if low salinity persists during extensive periods (autumn/winter/spring) $E$. marinus population will extinguishes after 3 years, under such conditions. According to simulations, if low salinity occurs for shorter periods (winter/early spring) E. marinus biomass and density remains stable for, at least, 11 years. This type of models may be important in assessing the impacts on local coastal areas caused by global effects, such as the rising of global temperature, which is expected to rise sea level and change precipitation and other local climate conditions. (C) 2002 Elsevier Science B.V. All rights reserved.
\end{abstract}

Keywords: Model; Density; Biomass; Echinogammarus marinus; Secondary production; Salinity; Precipitation; Global effects

* Corresponding author. Tel.: + 351-239-836386; fax: + 351-239-823603.

E-mail address: imartins@ci.uc.pt (I. Martins). 


\section{Introduction and study site}

Echinogammarus marinus (Amphipoda, Gammaridae) is very well adapted to life in estuaries, since it is a strongly euryhaline amphipod, able to support long emersion periods (Dorgelo, 1973; Pinkster and Broodbakker, 1980). The Mondego estuary $\left(40^{\circ} 08^{\prime} \mathrm{N} 8^{\circ} 50^{\prime} \mathrm{W}\right)$ (Fig. 1) is the southern most limit of this species known distribution, which extends from Norway to Portugal (Maren, 1975a,b; Marques and Bellan-Santini, 1993). In the Mondego estuary, E. marinus is the most abundant species of intertidal communities on hard substrata (Marques et al., 1993b), constituting an important prey for upper trophic levels, namely for birds (Múrias et al., 1996, 1997). E. marinus occurs in close association with Fucus vesiculosus (Phaeophyta, Fucales), which constitutes an eulittoral belt on hard substrates. Rocky margins make up about $60 \%$ of the perimeter of the Mondego estuary, representing therefore a significant part of the intertidal area, and are essentially the result of the installation of human activities (harbour facilities, aquaculture farms, salt works). E. marinus is typically found underneath $F$. vesiculosus in association with muddy deposits, being less common on clean sands (Maren, 1975b; Marques and Nogueira, 1991). Previous studies on the biology, population dynamics, and productivity of E. marinus in the Mondego estuary (Marques and Nogueira, 1991;

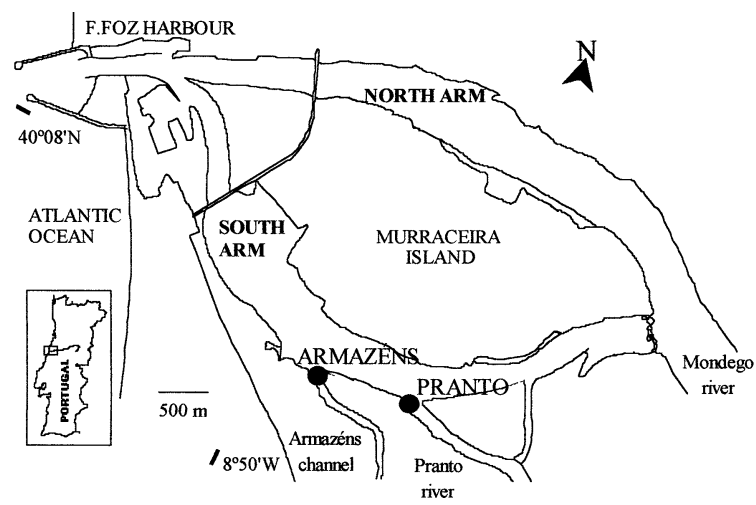

Fig. 1. The Mondego estuary with location of the field stations (Armazéns and Pranto) where the data used in the model were collected.
Maranhão et al., 2001) showed that density, percentage of ovigerous females, sex ratio, fecundity, and egg volume were affected by temperature and salinity. Another study conducted in the laboratory also revealed the influence of salinity and temperature on some aspects of the reproductive biology of E. marinus, namely, the duration of embryonic development, female's fecundity (brood size), and on growth of individuals (Maranhão and Marques, submitted).

The Mondego estuary consists of two arms, the north and the south (Fig. 1). The south arm constitutes a richer area with regard to macrofaunal abundance and biodiversity (Marques et al., 1993a). However, the hydrodynamics of the south arm is highly variable and strongly dependent both on the amount of precipitation and river flow management (Martins et al., 2001). In turn, river flow variations control salinity, current velocities, light extinction coefficients and N:P ratios in the system (Martins et al., 2001). The variation and interactions of such abiotic factors are likely to cause effects in the biotic factors. In fact, it was demonstrated that this hydrodynamics-controlling mechanism is responsible for the inter-annual variations of green macroalgal biomass observed in the system (Martins et al., 2001). For a more detailed characterisation of the system see also Flindt et al. (1997), Pardal et al. (2000), Martins et al. (2001), Maranhão et al. (2001).

The aim of the present work was to approach the possible effects of such hydrodynamics-controlling mechanism on the secondary production of benthic species in the Mondego estuary, taking as an example E. marinus. For this purpose, an ecological model for E. marinus population dynamics was developed. Based on prior empirical work, related both to E. marinus biology and the south arm's characteristics, salinity was considered as a main forcing function.

\section{Data set}

The model was developed and calibrated with data of E. marinus obtained by Maranhão et al. (2001) and Maranhão and Marques (submitted). In the first study, it was assessed the influence of 
environmental factors on the population dynamics, reproductive biology and productivity of this amphipod species in the Mondego estuary, from November 1994 to December 1995. Fortnightly biological samples were taken and individuals of E. marinus were collected, counted, sexed, and their length was determined. The determination of sex was based on the presence or absence of oostegites and/or broods (females), and of genital papillae (males). Animals without these features were considered to be juveniles. Non-brooding females were examined for the presence or absence of setae on the oostegites and classified as mature/adult or as non-reproductive/young females. If broods were present, eggs were counted to estimate fecundity, measured, and examined to determine the development stage. Additionally, temperature, salinity, dissolved oxygen, $\mathrm{pH}$, nutrients [dissolved inorganic $\mathrm{N}$ and $\mathrm{P}$ ] in the water column, organic matter in sediment, and biomass of $F$. vesiculosus, green macroalgae, and red macroalgae were also monitored. Some of the most important conclusions of this work were that sexual activity and recruitment take place continuously throughout the year and that fecundity increases with the size of females and is influenced by temperature and salinity. The relationships between total and cephalic length (TLCL) and between cephalic length and ash-free dry weight (CL-AFDW) were obtained from Marques and Nogueira (1991).

The second study, performed in the laboratory, aimed to investigate the influence of salinity and temperature on the duration of embryonic development, fecundity and growth of E. marinus (Maranhão and Marques, submitted). Individuals were exposed to different combined sets of temperature $\left(10,15\right.$ and $\left.20^{\circ} \mathrm{C}\right)$ and salinity $(10,15$, 20 and 25). According to results, the development time of embryos and female fecundity were significantly affected by temperature, and the number of embryos per brood increased with the size of females. E. marinus growth under laboratory conditions showed to be continuous through life but intrinsic growth rates were higher at $20{ }^{\circ} \mathrm{C}$ and lower at $10{ }^{\circ} \mathrm{C}$. Additionally, significant differences between growth rates of E. marinus under different salinity and temperature conditions were also observed.
Salinity data measured in the south arm of the Mondego estuary, during different years (1993Pardal et al., 2000; 1996-Martins et al., 2001, $2000 / 2001$ - Neto, in preparation) were used to make predictions about E. marinus density and biomass.

To initialise the model, real data of adult females and males were taken into account.

\section{Model formulation and conceptualisation}

According to some authors (Labat, 1991), the use of models which consider the size structure of the population is advantageous because there is a large amount of information available on the kinetics of different stages (larvae, juveniles, females, males), on the size structure of the animals and on the parameters which regulate them (Labat, 1991; Batchelder and Miller, 1989).

In the present model, the population of $E$. marinus was divided in four size classes: juveniles, young (non-reproductive) females, adult reproductive females and males, which constitute the state variables of the model. The flows between state variables are individuals $\mathrm{m}^{-2}$ time unit ${ }^{-1}$, while the units of the state variables are individuals $\mathrm{m}^{-2}$. The processes that regulate the number of individuals in each size class over time are: growth, which determines the number of individuals transferred from one size class to the next, death, which describes the number of individuals subtracted to each size class by mortality and reproduction/recruitment, which describes the input of newly hatched juveniles.

In addition to this population density module, the model also includes a biomass calculation module. The average weight of each size class is calculated from a Von Bertalanffy model of growth, which has been considered suitable to describe E. marinus growth (Marques, 1989; Marques and Nogueira, 1991; Maranhão and Marques, submitted). Then, the average weight of each size class is multiplied by the density of each group to obtain the biomass. The dependency of population density on biomass is described by 'recruitment' because the model assumes that the number of newly hatched juveniles depends on 
female cephalic length and, consequently, on female size. Such assumption is based on real data (Maranhão and Marques, submitted).

The model forcing functions are temperature and salinity, which affect reproduction/recruitment and growth. The model was written in STELLA 5.0 software and uses a time step of 15 days for ca. one-year (385 days). The time step of 15 days was chosen to allow a direct comparison with the real data, which were obtained from fortnightly collected samples (see Maranhão et al., 2001). Simplified STELLA diagrams of the model are shown in Fig. 2A and B.

\subsection{Growth, density and biomass}

Previous works (Marques, 1989; Marques and Nogueira, 1991; Maranhão and Marques, submitted) suggest that E. marinus growth is well predicted by the Von Bertalanffy model:

$L_{t}=L_{\infty} \times\left[1-\mathrm{e}^{-k\left(t-t_{0}\right)}\right]^{D}$,

$L_{t}$, length of the organism at a given moment $t$; $L_{\infty}$, maximum possible length of the organism; $t_{0}$, instant when the organism would have a length $=$ $0 ; k$, intrinsic growth rate; $D$, parameter that expresses metabolic deviations from the Von Bertalanffy $2 / 3$ rule, in this case $=1$.

Eq. (1) represents a modified and non-differential approach to estimate the instantaneous growth rate of an organism (Von Bertalanffy, 1957) in the following way:

$\frac{\mathrm{d} W}{\mathrm{~d} t}=h \times W^{d}-k \times W^{m}$,

$W$, weight; $h \times W^{d}, \quad$ anabolism; $k \times W^{m}$, catabolism.

The most usual values of $d$ and $m$ are $2 / 3$ and 1 , respectively (Von Bertalanffy, 1957). To estimate $h$ and $k$, following the same approach as Anastácio et al. (1999), the output values of Eq. (1) for $E$. marinus population were considered. The length of E. marinus individuals was transformed to dry weight according to a relationship previously determined for this species (Marques, 1989; Marques and Nogueira, 1991):

$\mathrm{DW}=1.592924 \times \mathrm{CL}^{3.94344}$,
DW, dry weight; CL, cephalic length.

Daily increases in the dry weight were then estimated following the 'least squares linear regression' method (Sokal and Rohlf, 1995) and fitted to Eq. (2), in order to calculate $h$ and $k$ for E. marinus. After this procedure, Eq. (2) was transformed to:

$\frac{\mathrm{d} W}{\mathrm{~d} t}=0.051229 \times W^{d}-0.018279 \times W^{m}$,

Eq. (4) was used to estimate the weight variations of all size classes.

Based on real data, it was also possible to estimate the average time that E. marinus individuals spend inside each size class until they are ready to be transferred to the next size class. This parameter was designated by days ${ }_{i-1, i}$. Additionally, the growth of E. marinus was also considered temperature-dependent, which was described by a temperature limitation factor $(f(T))$. Thus, the weight of an individual of $E$. marinus at the end of a size class $i\left(W_{i}\right)$ is calculated by:

$$
\begin{aligned}
W_{i}= & W_{i-1}+f(T) \times \text { days }_{i-1, i} \\
& \times\left(0.051229 \times W_{i-1}^{2 / 3}-0.018279 \times W_{i-1}\right),
\end{aligned}
$$

$W_{i-1}$, dry weight at the end of size class $i-1$.

The average weight of a size class $i$ is the arithmetic mean of its initial $\left(W_{i-1}\right)$ and final weight $\left(W_{i}\right)$. The initial weight of a certain size class is the final weight of the previous size one, except for juveniles. In this case, an average initial weight was considered (0.065369 mg AFDW), which was based on real data (Maranhão and Marques, submitted).

The biomass ( $\mathrm{mg}$ AFDW $\mathrm{m}^{-2}$ ) of each size class is calculated from its average weight multiplied by its density.

The number of individuals transferred to the next size class depends on a transfer rate, which was obtained by calibration.

\subsection{Effect of temperature on growth}

Since crustaceans are not able to control their body temperature to a significant degree, the typical response is that their metabolic rate varies 


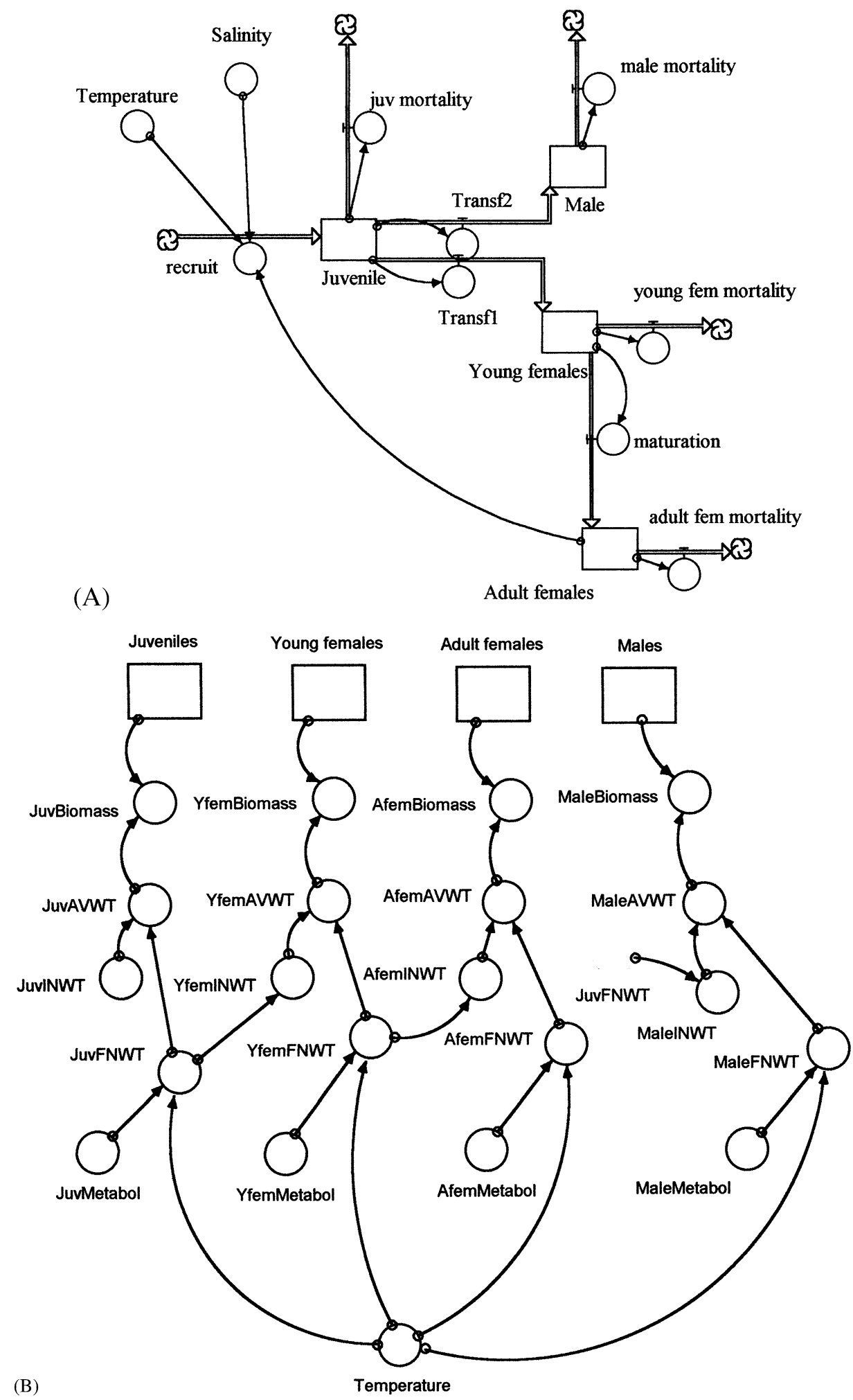

Fig. 2. (A) Simplified STELLA diagram of the density module of the model; (B) Simplified STELLA diagram of the biomass module of the model. juv, juveniles; yfem, young females; adfem, adult females; wt, weight. 


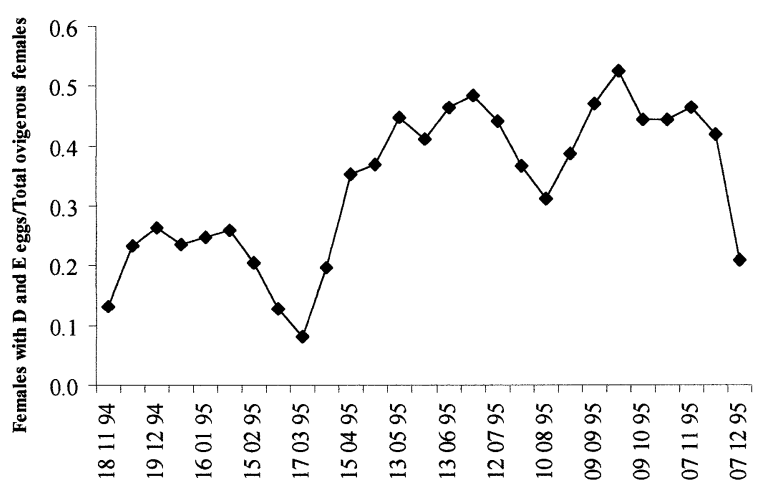

Fig. 3. Ratio between the number of adult females with D and E eggs and the total number of adult females.

directly with ambient temperature (Vernberg, 1983). To cope with this, the model uses a 'temperature optimum curve' (sensu EPA, 1985) to describe the effect of temperature on E. marinus growth. This formula was previously proposed by Najarian and Harleman (in EPA, 1985):

$f(T)=\left(\frac{T}{T_{\text {opt }}}\right)^{2.5} \times \mathrm{e}^{\left(1-\left(T / T_{\text {opt }}\right)^{2.5}\right)}$ for $T<T_{\text {opt }}$,

and

$f(T)=1-\left(\frac{T-T_{\mathrm{opt}}}{T_{\max }-T_{\mathrm{opt}}}\right)^{2}$ for $T \geq T_{\max }$,

$T$, temperature; $T_{\text {opt }}$, optimum temperature for growth; $T_{\max }$, maximum temperature at which growth ceases.

The final values for optimum and maximum temperature were estimated from field data and calibration (see Table 2).

\subsection{Recruitment}

Experiments carried out in the laboratory allowed to obtain significant regressions $(P<0.05)$ between the number of juveniles per female (NBJ) and the cephalic length of adult females $\left(\mathrm{CC}_{\mathrm{adfem}}\right)$ at different temperatures (Maranhão and Marques, submitted). Moreover, other authors (Vlasblom and Bolier, 1971) suggest that recruitment does not occur at low salinity $(<4)$. Taking into consideration these data, the number of newly hatched juveniles per female (NBJ) was expressed in the following way:

$$
\begin{aligned}
& \mathrm{NBJ}=0 \quad \text { for salinity } \leq 4, \\
& \mathrm{NBJ}=-70.3+62.8 \times \mathrm{CC}_{\text {adfem }} \\
& \quad(P<0.001) \text { for temperature }<15, \\
& \mathrm{NBJ}=-50.4+44.8 \times \mathrm{CC}_{\text {adfem }} \\
& \quad(P<0.05) \text { for temperature } \geq 15 \text { and }<23,
\end{aligned}
$$

$$
\begin{aligned}
& \mathrm{NBJ}=-11.7+12.2 \times \mathrm{CC}_{\text {adfem }} \\
& \quad(P<0.01) \text { for temperature } \geq 23,
\end{aligned}
$$

$\mathrm{CC}_{\mathrm{adfem}}$, cephalic length of adult females.

Eqs. (7b), (7c) and (7d) were obtained at 10, 15 and $20{ }^{\circ} \mathrm{C}$, respectively (Maranhão and Marques, submitted). After calibration they were used within the temperature ranges mentioned above.

According to field data obtained by Maranhão et al. (2001), the average ratio between females carrying eggs $\mathrm{D}$ and $\mathrm{E}$ and the total number of adult females is 0.33 (Fig. 3) Although, this value may be underestimated since females carrying eggs D may loose them, partially or even totally, due to sampling procedure (Drake and Arias, 1995), this rate was fixed in $0.0291 \mathrm{~d}^{-1}$, after calibration. Thus, recruitment was expressed as:

Recruitment $=\mathrm{NBJ} \times 0.0291 \times \mathrm{FA}$,

Because the model assumes a daily rate of females ready to release juveniles, meaning that the development time of such embryos has come to the end, the dependency between temperature and the development time of embryos suggested from the work of Maranhão and Marques (submitted) was not accounted by the model.

\subsection{Mortality}

The number of $E$. marinus individuals subtracted to each size class by mortality ( mort $_{i}$ ) was defined by:

$\operatorname{mort}_{i}=\operatorname{mortr}_{i} \times D_{i}$

mortr $_{i}$, mortality rate of size class $i ; D_{i}$, density of size class $i$.

The mortality rates of each size class were 
Table 1

Main equations of the model and basic explanation of the processes

\begin{tabular}{|c|c|}
\hline$\partial \mathrm{Juv} / \partial t=$ recruitment - mort $_{\text {juv }}-$ Transf $_{1}-$ Transf $_{2}$ & Variation of juvenile density per unit of time \\
\hline$\partial \mathrm{YFem} / \partial t=\operatorname{Transf}_{1}-$ mort $_{\mathrm{yfem}}-$ maturation & Variation of young female density per unit of time \\
\hline$\partial \mathrm{Male} / \partial t=$ Transf $_{2}-$ mort $_{\text {male }}$ & Variation of male density per unit of time \\
\hline$\partial \mathrm{AdFem} / \partial t=$ maturation - mort $_{\mathrm{adfem}}$ & Variation of adult female density per unit of time \\
\hline Recruitment $=(\mathrm{NBJ} \times f(S) \times f(T)) \times 0.0291 \times \mathrm{AdFem}$ & Number of newly hatched juveniles per unit of time \\
\hline $\mathrm{NBJ}=0$ for salinity $\leq 4$ & $\begin{array}{l}\text { Significant regressions }(P<0.05) \text { between the number of newly } \\
\text { hatched juveniles and females cephalic length and dependency of NBJ } \\
\text { on salinity and temperature }\end{array}$ \\
\hline $\begin{array}{l}\mathrm{NBJ}=-70.3+62.8 \times \mathrm{CC}_{\text {AdFem }} \text { for temperature }<15 \\
\mathrm{NBJ}=-50.4+44.8 \times \mathrm{CC}_{\text {AdFem }} \text { for temperature }\end{array}$ & \\
\hline$\geq 15$ and $<23$ & \\
\hline $\mathrm{NBJ}=-11.7+12.2 \times \mathrm{CC}_{\mathrm{AdFem}}$ for temperature $\geq 23$ & \\
\hline Bio $_{\text {Juv,Yfem,AdFem,Male }}=$ Juv, Yfem, AdFem, Male & Biomass of population groups \\
\hline$\times$ AvWeight $_{\text {Juv, }}$ Yfem, AdFem, Male & \\
\hline AvWeight $=\left(W_{i-1}+W_{i}\right) / 2$ & Average weight of population groups \\
\hline$W_{i}=W_{i-1}+f(T) \times \operatorname{days}_{i-1, i} \times\left(h \times W_{i-1}^{2 / 3}-k \times W_{i-1}\right)$ & Weight of E. marinus at the end of size class $i$ \\
\hline
\end{tabular}

Table 2

Symbols, description, units, values and estimation method of parameters and initial values used in the model

\begin{tabular}{|c|c|c|c|}
\hline Symbol & Description & Units & Used value \\
\hline JuvInit & Initial density of juveniles & $\begin{array}{l}\text { individuals } \\
\mathrm{m}^{-2}\end{array}$ & 144/experimental \\
\hline$W i_{\text {juv }}$ & Initial weight of juveniles & $\mathrm{mg}$ & $0.065369 /$ experimental \\
\hline DaysJuv & Juvenile duration & days & $60 /$ experimental \\
\hline mort $_{\text {juv }}$ & Juvenile mortality & per day & $0.05 /$ experimental, calibration \\
\hline Trans $_{1}$ & Rate of transfer from juveniles to young females & per day & $0.0085 /$ calibration \\
\hline Trans $_{2}$ & Rate of transfer from juveniles to males & per day & $0.009 /$ calibration \\
\hline MaleInit & Initial density of males & $\begin{array}{l}\text { individuals } \\
\mathrm{m}^{-2}\end{array}$ & 41/experimental \\
\hline DaysMales & Male duration & days & $500 /$ experimental \\
\hline mort $_{\text {male }}$ & Male mortality & per day & 0.024/experimental,calibration \\
\hline YfemInit & Initial density of young females & $\begin{array}{l}\text { individuals } \\
\mathrm{m}^{-2}\end{array}$ & $30 /$ experimental \\
\hline DaysYFem & Young females duration & days & 200/experimental, calibration \\
\hline mort $_{\mathrm{yfem}}$ & Young females mortality & per day & $0.025 /$ experimental, calibration \\
\hline maturation & Rate of transfer from young to adult females & per day & $0.0225 /$ calibration \\
\hline AfemInit & Initial density of adult females & $\begin{array}{l}\text { individuals } \\
\mathrm{m}^{-2}\end{array}$ & $30 /$ experimental \\
\hline DaysAFem & Adult females duration & days & 200/experimental, calibration \\
\hline mort $_{\mathrm{afem}}$ & Adult females mortality & per day & $0.03 /$ experimental, calibration \\
\hline$T_{\text {opt }}$ & Optimum temperature for E. marinus growth & ${ }^{\circ} \mathrm{C}$ & 20/experimental, calibration \\
\hline$T_{\max }$ & Upper temperature limit for E. marinus growth & ${ }^{\circ} \mathrm{C}$ & $35 /$ experimental, calibration \\
\hline Salimit & Salinity limit at which recruits die & & 4/literature \\
\hline
\end{tabular}

based on real data obtained under laboratorial conditions by Maranhão (unpublished data) followed by calibration (see Table 2).

The main equations of the model are shown in Table 1.

\section{Results}

Predicted E. marinus total density follows the same pattern of variation of the observed results, showing an initial early spring peak, followed by a 


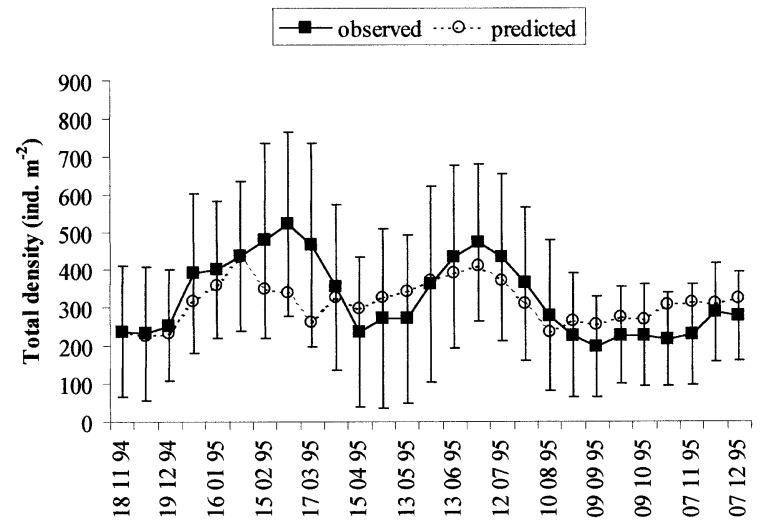

Fig. 4. Observed \pm standard deviation and predicted variation of the total density of E. marinus (individuals $\mathrm{m}^{-2}$ ).

$\mathbf{A}$
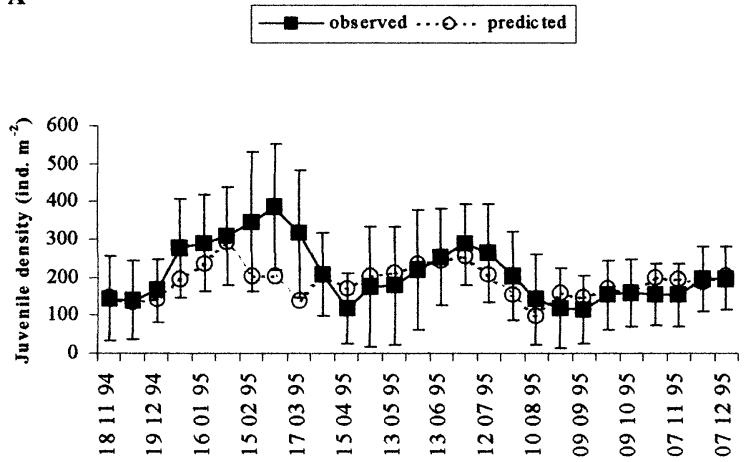

B

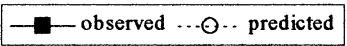

?

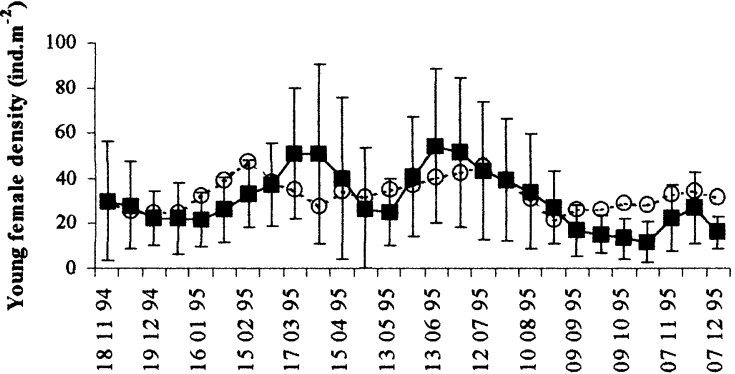

decrease and then showing a second summer peak (Figs. 4 and 5). Although most of the predicted values are within the range of the observed values \pm standard deviation, the early-spring predicted density peak is lower and occurs earlier than the real one. This tendency is also clear in juveniles and young females predicted variation (Fig. 5A and B).

In the case of biomass, the simulated summer peak is considerably lower than the real peak (Figs. 6 and 7), which is mostly due to the underestimation of male biomass (Fig. 7D), although adult female biomass is overestimated by the model (Fig. 7C).

The model is stable for long term simulations (ca. 11 years) (Fig. 8), which apparently supports the internal logic of the model (Jørgensen, 1994).

C
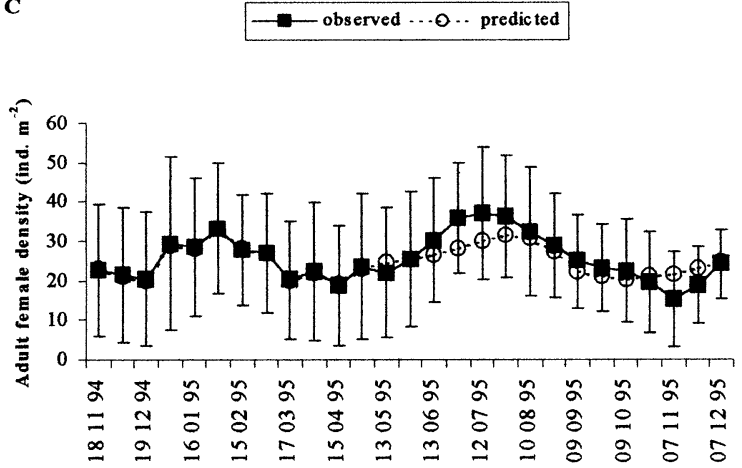

D

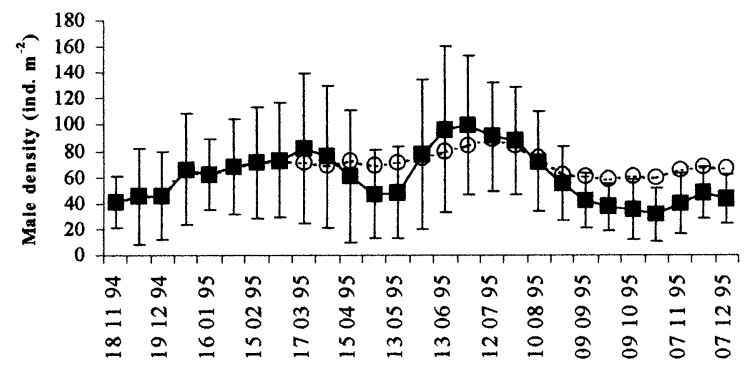

Fig. 5. Observed \pm standard deviation and predicted variation of the density variation by population groups: (A) juveniles; (B) young females; (C) adult females; (D) males. 


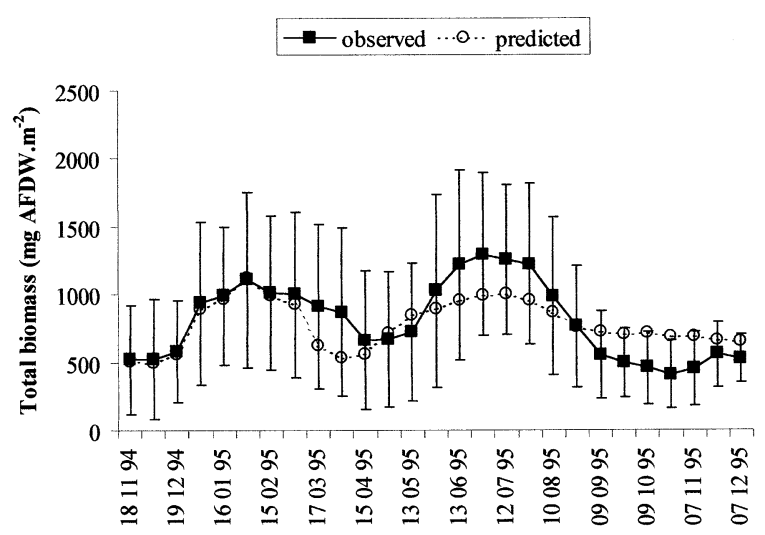

Fig. 6. Observed \pm standard deviation and predicted variation of the total biomass of $E$. marinus $\left(\mathrm{mgAFDW}^{-2}\right.$ ).

Sensitivity analysis suggests that the parameters related to the biomass calculation module (e.g. $h$ and $k$ ) are more sensitive than density related

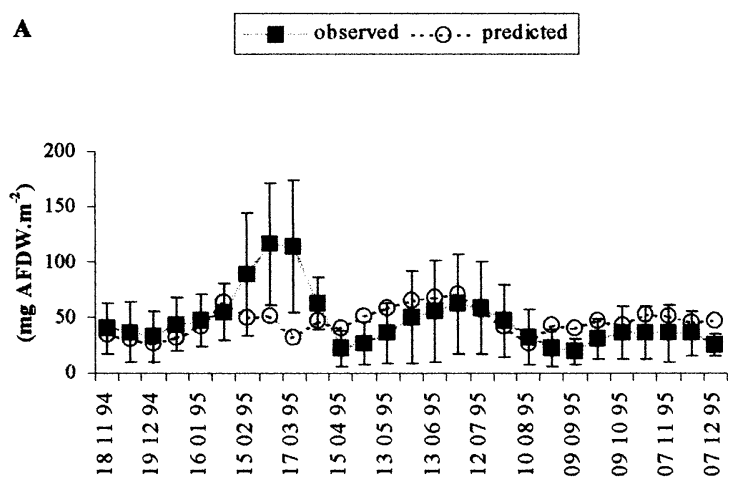

B
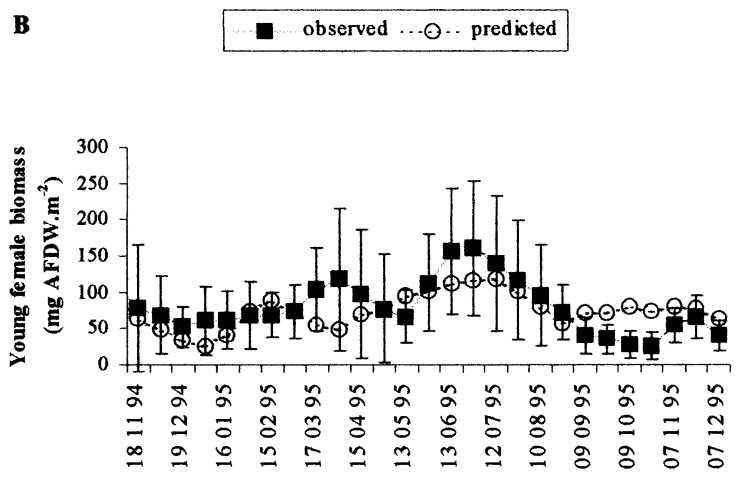

parameters (e.g. Transf ${ }_{1}$, mortality rates). For instance a $50 \%$ decrease of $k$ (the constant related with catabolism) in males, increases male biomass substantially in relation to the basic simulation (Fig. 9). The sensitivity of the model in relation to the forcing functions is also important and different for E. marinus density and biomass. For example, a $25 \%$ decrease of the optimum temperature $\left(T_{\text {opt }}\right)$ causes almost no change in the population density but it contributes to a significant decrease of the summer biomass peak (Fig. $10 \mathrm{~A}$ and $\mathrm{B}$ ).

The model was used to make predictions about E. marinus density and biomass under salinity data from different years (1993, 1996, 2000/2001) obtained in the Mondego estuary. Salinity variation during these years are shown in Fig. 11. It becomes clear that E. marinus population is negatively affected by low salinity and that, the negative effects are higher for extensive periods with
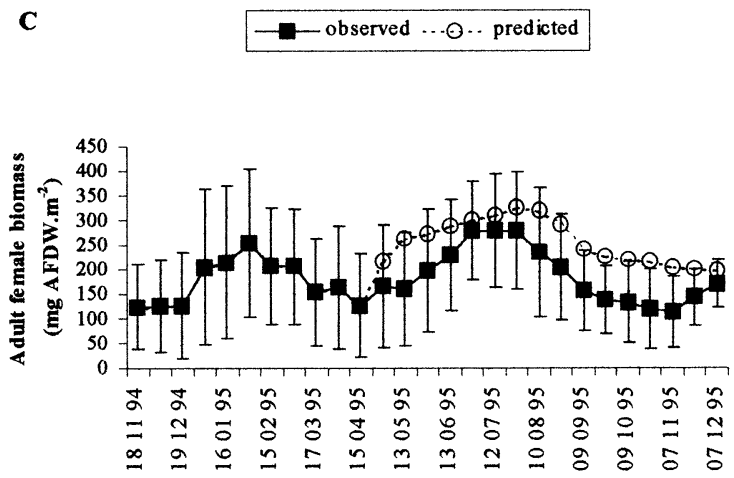

D

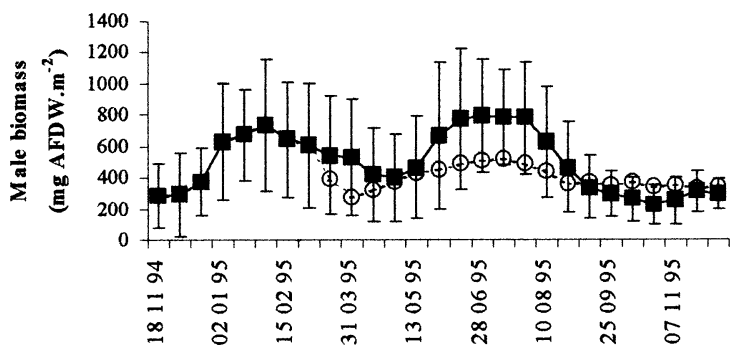

Fig. 7. Observed \pm standard deviation and predicted variation of the biomass variation by population groups: (A) juveniles; (B) young females; (C) adult females; (D) males. 


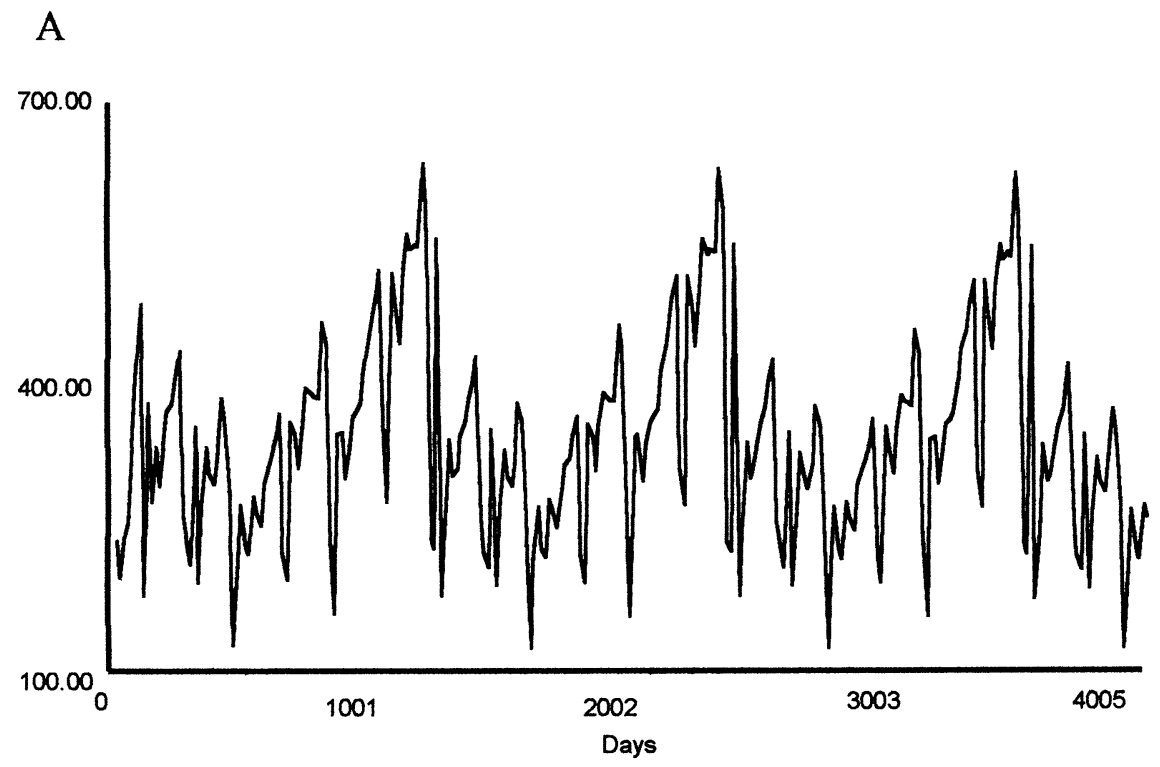

B

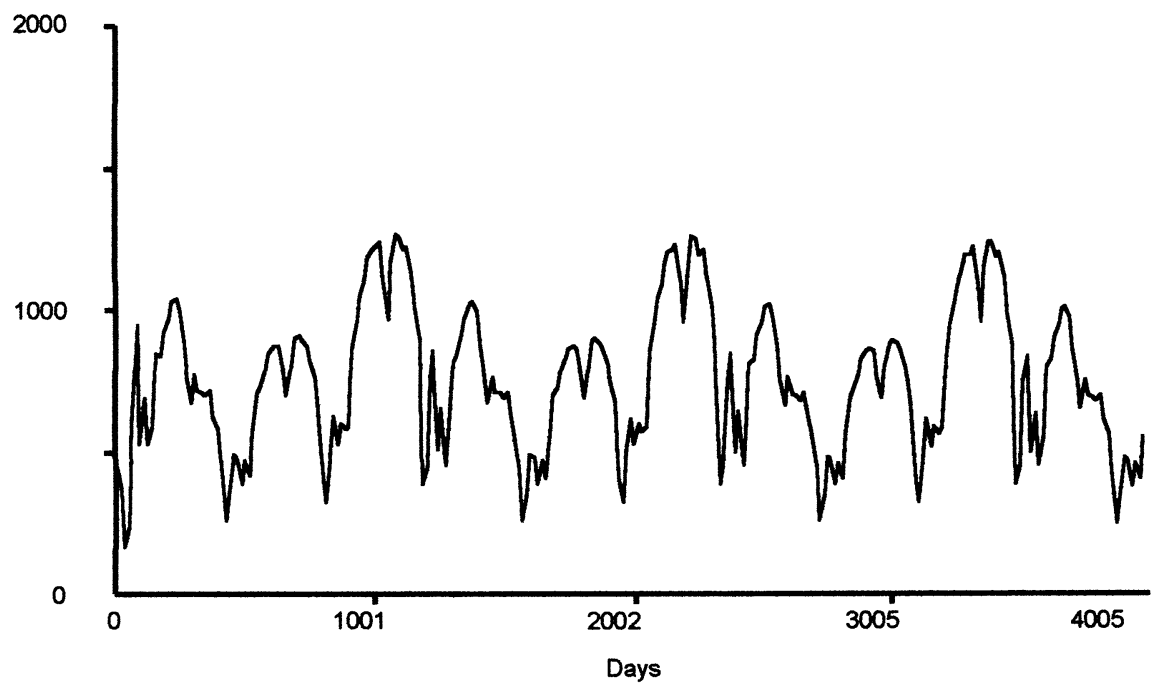

Fig. 8. Long run simulation ( $\approx 11$ years) for E. marinus total density (ind $\mathrm{m}^{-2}$ ) $(\mathrm{A})$ and total biomass $\left(\mathrm{mgFDW} \mathrm{m}^{-2}\right)(\mathrm{B})$.

low salinity values, such as in 2000/2001 (Figs. 11 and 13). Initially, E. marinus density suffers a more dramatic reduction than biomass. Later on, E. marinus density and biomass vary according to a similar pattern (Fig. 12).

\section{Discussion and conclusions}

This model presents an approach to estimate variations on E. marinus population using a density- and a biomass-estimation module. There are 
tight connections between the two modules of the model. For example, the biomass of each size class depends on its density. Additionally, the model also establishes a dependency of density on biomass, through the process of 'recruitment'. In fact, the number of juveniles was described as a

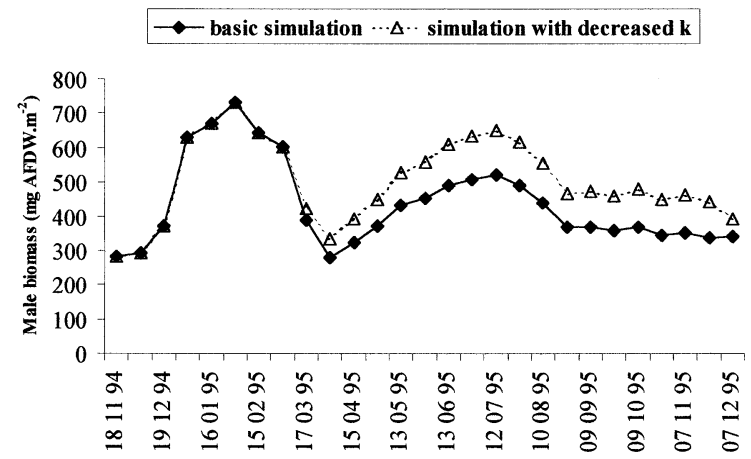

Fig. 9. Variation of male biomass using the value of $k$ (constant related with catabolism) estimated for all population and considering a hypothetical lower $k$, in accordance to decreasing metabolic rate with increasing age.

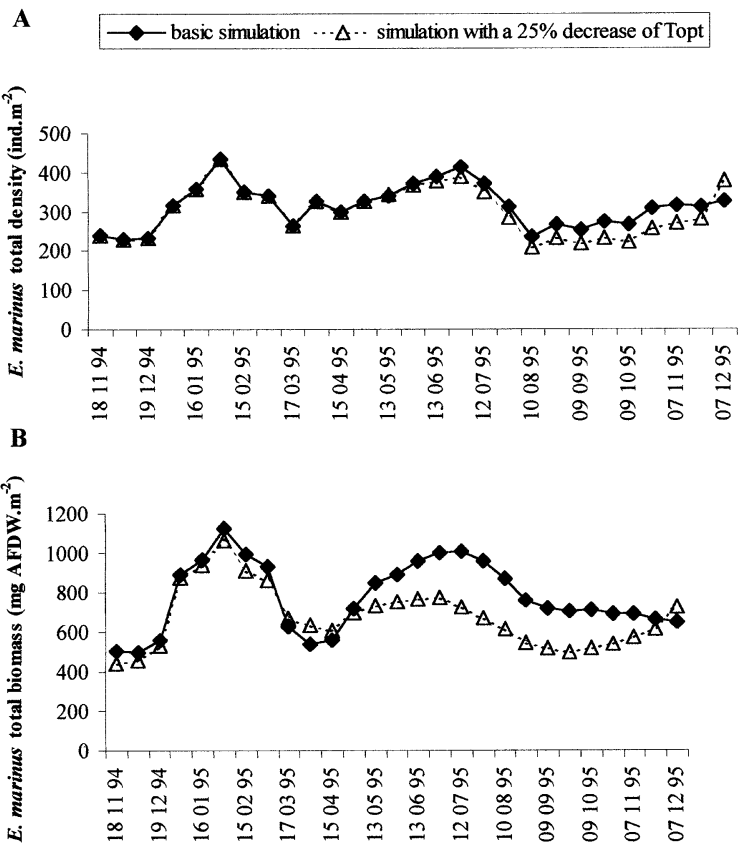

Fig. 10. Variation of total E. marinus density (A) and biomass (B) assuming a $25 \%$ decrease on the optimum temperature value $\left(T_{\mathrm{opt}}=15\right)$.

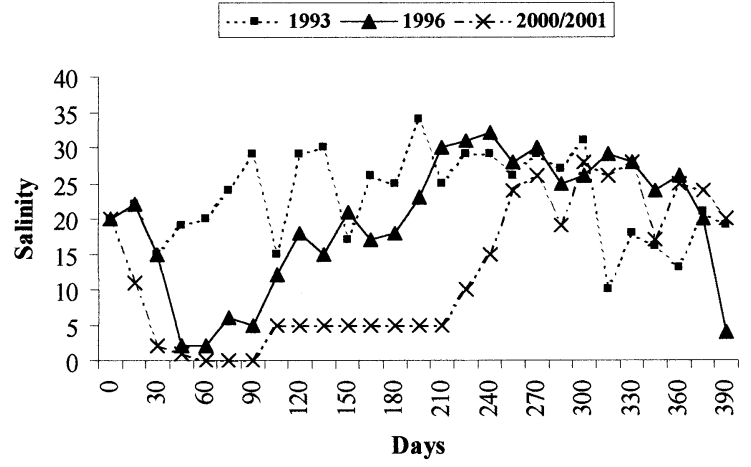

Fig. 11. Salinity variation measured in the Mondego estuary during 1993 (A), 1996 (B) and 2000-2001 (C).
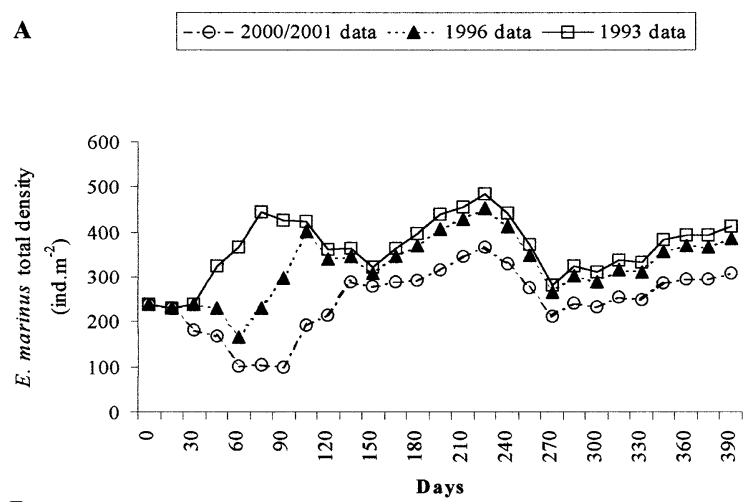

B

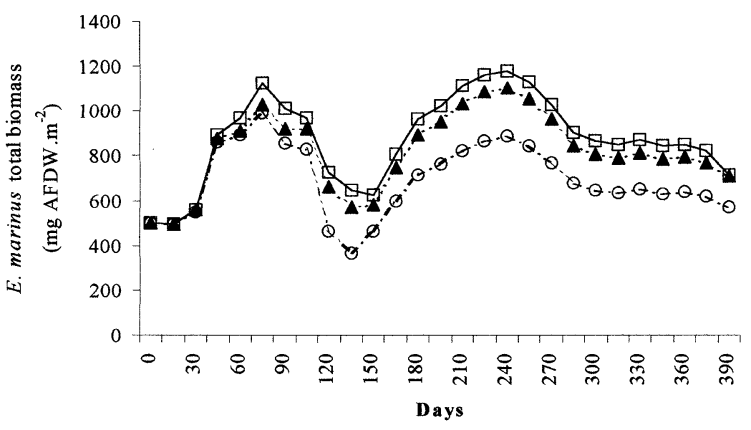

Fig. 12. One-year simulations of E. marinus total density (A) and total biomass (B) using salinity data from 1993 (squares), 1996 (triangles) and 2000-2001 (circles).

dependency on female cephalic length, which in turn depends on female weight.

Furthermore, according to real data (Maranhão et al., 2001), the model assumes that the recruitment of E. marinus also depends on tem- 
perature and salinity, which seems to be true also for other amphipod species (e.g. Caprela sp., Takeuchi and Hirano, 1991; Corophium sp., Cunha et al., 2000b; Gammarus sp, Steele and Steele, 1973). Several authors refer the case of the negative effects that low salinity have on amphipods recruitment (Pinkster and Broodbakker, 1980; Cunha et al., 2000a; Maranhão et al., 2001). In the case of E. marinus, its recruitment seems to be inhibited within a salinity range of 4-7 (Vlasblom and Bolier, 1971). In the present work, a salinity of four was assumed as the lowest limit for recruitment. However, due to the importance of this parameter and the significant salinity fluctuations verified in the system, it would be wise to determine the exact value of salinity tolerance of E. marinus population in the Mondego estuary.

The discrepancies between predictions and observations are more evident for the biomass results than for density, which is related to the need of a more accurate determination of biomass-related parameters. In fact, when considering a size-class model to estimate biomass variations, it is expected that different size classes have different parameters in accordance with its size, age, etc. This fact became evident from Fig. 9, where the basic simulation for males is compared to a simulation, which uses a lower value of $k$ for males, in accordance with the decrease of metabolic rates with increasing age (Von Bertalanffy, 1957). In this simulation, male biomass increased to values more close to the real ones. Thus, in the future, a higher effort should be given to calculate the metabolic-related parameters of the different size classes.

According to model results, the occurrence of periods with low salinity has negative impacts both on E. marinus density and biomass. In the Mondego estuary, low salinity values occur mostly in winter/spring periods depending on precipitation and river flow management (Martins et al., 2001). Thus, in years like 1996, characterised by low salinity during winter months, E. marinus density decreases considerably at this time of the year, but it recovers in spring with the rise of salinity values. Since the major effect of low salinity is the reduction on the number of newly hatched juveniles (recruitment), E. marinus biomass is not so affected as density. Nevertheless, it also shows decreased values compared to a dry year, such as 1993. According to the model, even if 1996 weather conditions would prevail for ca. 11 years, E. marinus density and biomass would be almost stable, showing only a very slight

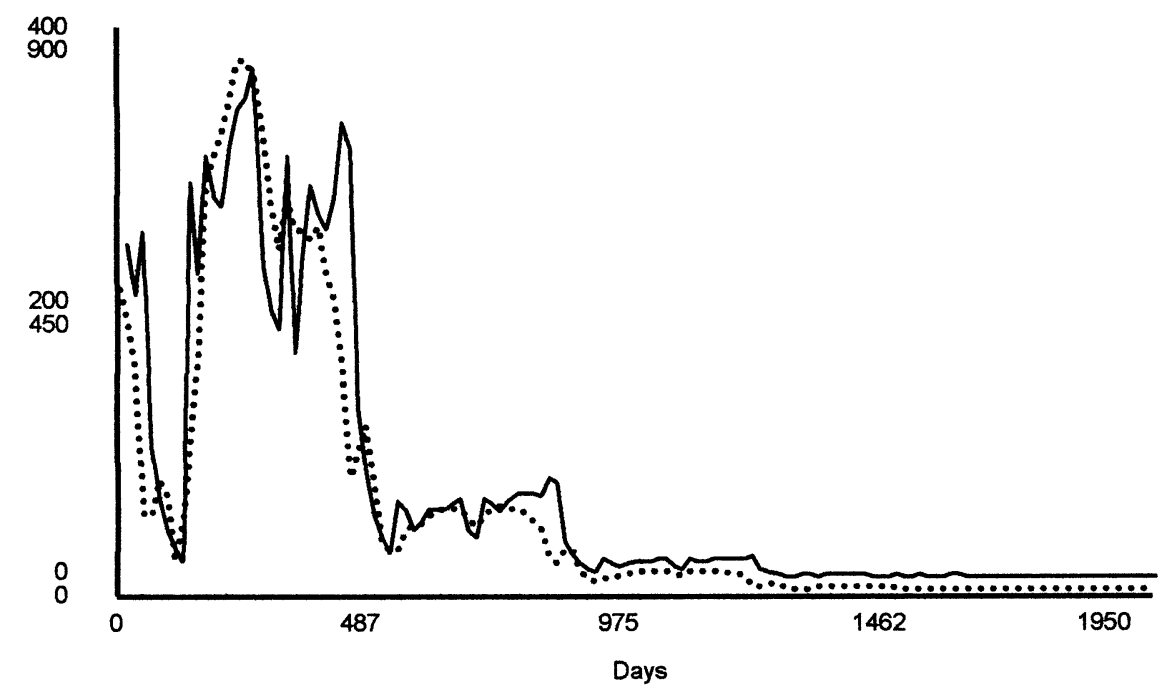

Fig. 13. Five-year simulation of E. marinus total density (full line: $0-400$ individuals $\mathrm{m}^{-2}$ ) and total biomass (dotted line: $0-900$ mg AFDW $\mathrm{m}^{-2}$ ) using 2000-2001 salinity data. The population extinguishes after ca. 3 years. 
decrease. On the contrary, according to the model, the occurrence of intensive and continuous precipitation for at least 6 months, such as was the case in 2000/2001 for the Mondego estuary, would lead to E. marinus extinction after ca. 3 years under such rainy autumn-winter-spring conditions.

At the system level, the present results are important because they suggest that, such as in the case of macroalgal primary productivity (Martins et al., 2001), also secondary production seems to be affected by the hydrodynamics of the system due to impacts on salinity.

Furthermore, since the expected rising of global temperature is expected to rise sea level and change precipitation and other local climate conditions, this type of models may be extremely useful in understanding global effects on local coastal systems.

\section{Acknowledgements}

The present work was supported by JNICT/ FCT (Portuguese National Institution for Scientific Research) by a Ph.D. grant to P. Maranhão (FMRH/BD/822/93-PRAXIS XXI/BD/14652/97). The authors are indebted to Dr João Neto, from IMAR, Department of Zoology of the University of Coimbra, for providing information regarding salinity data.

\section{References}

Anastácio, P.M., Nielsen, S.N., Marques, J.C., 1999. CRISP (crayfish and rice integrated system of production): 2. Modelling crayfish (Procambarus clarkii) population dynamics. Ecol. Model. 123, 5-16.

Batchelder, H.P., Miller, C.B., 1989. Life history and population dynamics of Metridia pacifica: results from simulation modelling. Ecol. Model. 48, 113-136.

Cunha, M.R., Moreira, M.H., Sorbe, J.C., 2000a. 'Predicting amphipods' brood size variation in brackish environments: na empirical model for Corophium multisetosum Stock, 1952 (Corophiidae) in Ria de Aveiro (NW Portugal). J. Exp. Mar. Biol. Ecol. 248, 207-223.

Cunha, M.R., Sorbe, J.C., Moreira, M.H., 2000b. The amphipod Corophium multisetosum (Corophiidae) in Ria de Aveiro (NW Portugal). I. Life history and aspects of reproductive biology. Mar. Biol. 137, 637-650.

Dorgelo, J., 1973. Comparative ecophysiology of gammarids (Crustacea: Amphipoda) from marine, brackish, and freshwater habitats exposed to the influence of salinity-temperature combinations. III: Oxygen uptake. Neth. J. Sea Res. 7, 253-266.

Drake, P., Arias, A.M., 1995. Distribution and production of Microdeutopus gryllotalpa (Amphipoda: Aoridae) in a shallow coastal lagoon in the Bay of Cádiz, Spain. J. Crust. Biol. 15, 454-465.

EPA (Environmental Protection Agency, USA), 1985. Rates, constants, and kinetics. Formulations in surface water quality modelling, 2nd ed., 455 p.

Flindt, M.R., Kamp-Nielsen, L., Marques, J.C., Pardal, M.A., Bocci, M., Bendoricho, G., Nielsen, S.N., Jørgensen, S.E., 1997. Description of the three shallow estuaries: Mondego River (Portugal), Roskilde Fjord (Denmark) and the Lagoon of Venice (Italy). Ecol. Model. 102, 17-31.

Jørgensen, S.E., 1994. Fundamentals of Ecological Modelling, 2nd ed. Elsevier, Amsterdam, p. 628.

Labat, J.-P., 1991. Model of a shrimp population (Philocheras trispinosus) I-Simulation of the size structure. Ecol. Model. 53, 75-93.

Maranhão, P., Bengala, N., Pardal, M., Marques, J.C., 2001. The influence of environmental factors on the population dynamics, reproductive biology and productivity of Echinogammarus marinus Leach (Amphipoda, Gammaridae) in the Mondego estuary (Portugal). Acta Oecol 22, 139-152.

Maren, M.J., 1975a. Some notes on the intertidal gammarids (Crustacea, Amphipoda) from the Atlantic coast of the Iberian Peninsula. Beaufortia 23, 153-168.

Maren, M.J., 1975b. The biology of Chaetogammarus marinus (Leach) and Eulimnogammarus obtusatus (Dahl), with some notes on other intertidal gammarid species (Crustacea, Amphipoda). Bijdr. Dierk. 45, 204-224.

Marques, J.C., 1989. Amphipoda (Crustacea) bentónicos da costa portuguesa: estudo taxonómico, ecológico e biogeográfico. Ph.D. thesis, Universidade de Coimbra, Portugal, $394 \mathrm{p}$.

Marques, J.C., Nogueira, A., 1991. Life cycle, population dynamics and production of Echinogammarus marinus (Leach) (Amphipoda) in the Mondego estuary (Portugal). Oceanol. Acta 11, 213-223.

Marques, J.C., Bellan-Santini, D., 1993. Biodiversity in the ecosystem of the Portuguese continental shelf: distributional ecology and the role of benthic amphipods. Mar. Biol. 115, 555-564.

Marques, J.C., Maranhão, P., Pardal, M.A., 1993a. Human impact assessment on the subtidal macrobenthic community structure in the Mondego estuary (western Portugal). Estuar. Coast. Shelf Sci. 37, 403-419.

Marques, J.C., Rodrigues, L.B., Nogueira, A., 1993b. Intertidal macrobenthic communities structure in the Mondego estuary (Western Portugal): reference situation. Vie Milieu 43, 177-187.

Martins, I., Pardal, M.A., Lillebø, A.I., Flindt, M.R., Marques, J.C., 2001. Hydrodynamics as a major factor con- 
trolling the occurrence of green macroalgal blooms in a eutrophic estuary: a case study on the influence of precipitation and river management. Estuar. Coast. Shelf Sci. 52, 165-177.

Múrias, T., Cabral, J.A., Marques, J.C., Goss-Custard, J.D., 1996. Short-term effects of intertidal macroalgal blooms on the macrohabitat selection and feeding behaviour of waders in the Mondego estuary (West Portugal). Estuar. Coast. Shelf Sci. 43, 677-688.

Múrias, T., Cabral, J.A., Lopes, R., Marques, J.C., 1997. Low-water use of the Mondego estuary (West Portugal) by waders (Charadrii). Ardeola 44 (1), 79-91.

Pardal, M.A., Marques, J.C., Metelo, I., Lillebø, A.I., Flindt, M.R., 2000. Impact of eutrophication on the life cycle, population dynamics and production of Ampithoe valida (Amphipoda) along an estuarine spatial gradient (Mondego estuary, Portugal). Mar. Ecol. Prog. Ser. 196, 207-219.

Pinkster, S., Broodbakker, N.W., 1980. The influence of environmental factors on distribution and reproductive success of Eulimnogammarus obtusatus (Dahl, 1938) and other estuarine gammarids. Crustaceana (Suppl.) 6, 225-241.

Sokal, R.R., Rohlf, F.J., 1995. Biometry, 3rd ed. Freeman Press, New York, p. 887.

Steele, D.H., Steele, V.J., 1973. The biology of Gammarus (Crustacea, Amphipoda) in the northwestern Atlantic. VII. The duration of embryonic development in five species at various temperatures. Can. J. Zool. 51, 995-999.

Takeuchi, I., Hirano, R., 1991. Growth and reproduction of Caprella danilevskii (Crustacea: Amphipoda) reared in the laboratory. Mar. Biol. 110, 391-397.

Vernberg, F.J. 1983. 1-Respiratory adaptations. The Biology of Crustacea, vol. 8, Environmental Adaptations. Editorin-chief: Bliss, D.E. In: Vernberg, F.J., Vernberg, W.B. (Eds.), Academic Press, Inc., New York, 383 pp.

Vlasblom, A.G., Bolier, G., 1971. Tolerance of the embryos of Marinogammarus marinus and Orchestia gammarella to lowered salinities. Neth. J. Sea Res. 5, 255-268.

Von Bertalanffy, L., 1957. Quantitative laws in metabolism and growth. Q. Rev. Biol. 32 (3), 217-231. 